\title{
INÉDITOS VIÁVEIS: DIALOGICIDADE, INTERCULTURALIDADE E LIBERTAÇÃO
}

Giselle Moura Schnorr ${ }^{1}$

\section{Resumo}

Este escrito visa tecer algumas aproximações entre os temas: dialogicidade (FREIRE, 1987), interculturalidade (FORNET-BETANCOURT, 2001), descolonização (FANON, 2005) e libertação. Este tecer parte da educação filosófica como permanente reeducação do pensar (SCHNORR, 2015) e a Filosofia como é um contínuo movimento de saberes de todas as parte do mundo, encontro de povos, que na maioria dos casos se deu no confronto, na violência colonial, promovendo, também, epistemicídios, ou seja, assassinando, negando a produção de conhecimento de determinados povos, no caso brasileiro, o negro e indígena, nos convida a reflexão sobre "inéditos viáveis" para a transformação da filosofia (FORNET-BETANCOURT, 2001), portanto, para descolonização do pensar e do enfrentamento dos epistemicídios que se reproduzem entre nós.

Palavras-chave: Interculturalidade. Dialogicidade. Libertação.

\section{VIABLE UNPUBLISHED: DIALOGICITY, INTERCULTURALITY AND LIBERATION}

\footnotetext{
Abstract

This paper outlines approximations between the following themes: dialogicity (FREIRE, 1987), interculturality (Fornet-Betancourt, 2001), 
decolonization (FANON, 2005) and liberation. Firstly, it presents the philosophical education as a permanent reeducation of thinking $(\mathrm{SCH}-$ NORR, 2015); secondly, the Philosophy as a continuous movement of knowledge from all over the world, a confluence of peoples, which mainly took place in conflict and colonial violence. Knowledge emerges in a context of epistemicides, that is, excluding so many ethnicities from it's production. In Brazil, black and indigenous people are inviting us to reflect on the "unprecedented viable" for Philosophy transformation (Fornet-Betancourt, 2001), to decolonize the thinking and to face the epistemicides reproducing among us.

Keywords: Interculturality. Dialogicity. Release.

\section{Palavras iniciais}

"Inéditos viáveis" é uma expressão cunhada por Paulo Freire para se referir ao futuro a ser construído desde o presente, na ação-reflexão-ação, na aposta no sonho possível e na utopia que virá, desde que os que fazem a história assim queiram, resistindo diante de "situações-limites" situações de desesperança, mas que podem ser superadas por meio de ações de libertação, atuando na história desde o contexto, produzindo novas percepções de mundo e novos conhecimentos, transformando, intervindo. Localizamos nestas expressões a ontologia em Freire:

No momento em que estes as percebem [as situações-limites] não mais como uma "fronteira entre o ser e o nada, mas como uma fronteira entre o ser e o ser mais", se fazem cada vez mais críticos na sua ação, ligada àquela percepção. Percepção em que está implícito o inédito viável como algo definido, a cuja concretização se dirigirá sua ação (Freire, 1987, p. 94).

A dimensão ontológica de ser mais em Freire é importante para compreensão de sua obra, seja do ponto do reconhecimento do ser humano como histórico, como ser de possibilidades, como de sua compreensão dialética de conhecimento:

Ninguém sabe tudo, assim como ninguém ignora tudo. O saber começa com a consciência do saber pouco. [...] Se tivéssemos o saber absoluto, já não poderíamos continuar sabendo, pois que este seria um saber que não estaria sendo. [...] E é por isto que todo saber novo se gera num saber que passou a se velho, o qual, anteriormente, gerando-se num outro saber que também siona: não são "o contorno infranqueável onde terminam as possibilidades, mas a margem real onde começam todas as possibilidades"; não são "a fronteira entre o ser e o nada, mas a fronteira entre o ser o ser mais" (mais ser). Álvaro Vieira Pinto, Consciência e Realidade Nacional. Rio de Janeiro, ISEB, 1960, vol. II, p. 284 (Freire, 1987, p. 90). Ver também Pedagogia da Esperança (Freire, 1999, p. 11, 205-207) 
se tornara velho, se havia instalado com saber novo (Freire, 2010 p. 47).

A desumanização, entendida como "o resultado de uma ordem injusta que gera a violência dos opressores, o que, por outro lado, desumaniza os oprimidos" é, para Freire, uma distorção da vocação histórica (ontológica) de fazer-se mais plenamente humano, negação do ser mais. Enfrentar esse problema é reconhecer a necessidade de superação das relações que negam - proíbem - que os outros sejam (Idem, 1987, p.74-75).

Em Pedagogia da Esperança: Um reencontro com a Pedagogia do oprimido Freire retoma o problema da humanização-desumanização, conectando-a às amarras concretas da ordem econômica, política, social que estão nos condenando à desumanização com o neoliberalismo e seu discurso de "modernidade"; com o "discurso ideológico" de incompetência das esquerdas; abordando o esfacelamento do socialismo autoritário e reafirmando que: "Enquanto a violência dos opressores faz dos oprimidos homens proibidos de ser, a resposta destes à violência daqueles se encontra infundida do anseio de busca do direito de ser (Ibidem,1999, p.93-97).

Estas considerações nos convidam a revisitar a dialética entre conhecimento e transformação da realidade como polos distintos mas interconectados. Ainda que a estrutura mestra da dominação e opressão tenha como matriz fundamental a exploração econômica, esta deve ser compreendida, segundo Freire, como estrutura que nos condiciona, mas que não deve nos determinar. Classe gera o saber de classe e serve como ponto de interseção para os outros pontos de opressão/ dominação, como raça e gênero, temas pouco presentes nos primeiros escritos de Freire:

Nunca entendi que as classes sociais, a luta entre elas, pudessem explicar tudo, até a cor das nuvens numa terça-feira à tardinha, daí que jamais tenha dito que a luta de classes, no mundo moderno, era o motor da história. Mas, por outro lado, hoje ainda e possivelmente por muito tempo, não é possível entender a história sem as classes sociais, sem seus interesses em choque. Aa luta de classes não é o motor da história, mas certamente é um deles" (ibidem, 1999, p. 91).

Pedagogia do Oprimido, teve sua primeira edição em língua inglesa (1968), com grande alcance na sociedade norte-americana. Em Pedagogia da Esperança: Um reencontro com a Pedagogia do oprimido Freire rememora diálogos, alguns por cartas, que teve com feministas daquele país, que o levaram a refletir acerca da linguagem sexista que utilizava em sua mensagem para a construção de uma educação libertadora. No exercício dialógico, não sem resistências, reviu seu modo de escrita reconhecendo que a linguagem expressa a cultura e esta comunica os sentidos da ética que perpassa as relações humanas. 
Comentando cartas que recebera realiza uma escrita conectiva, que hoje reconhecemos como prática intercultural, portanto, dialógica, observando suas contradições frutos do patriarcado:

É que diziam elas, com suas palavras, discutindo a opressão, a libertação, criticando, com justa indignação, as estruturas opressoras, eu usava, porém, uma linguagem machista, portanto discriminatória, em que não havia lugar para as mulheres. Quase todas as que me escreveram citavam um trecho ou outro do livro, como o que agora, como exemplo, escolho eu mesmo: "Desta forma, aprofundando a tomada de consciência da situação, os homens se 'apropriam' dela como realidade histórica, por isto mesmo, capaz de ser transformada por eles." E me perguntavam: "Por que não, também, as mulheres?" [...] Em certo momento de minhas tentativas ideológicas, de justificar a mim mesmo, a linguagem machista que usava, percebi a mentira ou a ocultação da verdade que havia na afirmação: "Quando falo homem, a mulher está incluída". [...] Nenhum homem se acharia incluído no discurso de nenhum orador ou no texto de nenhum autor que escrevesse: "As mulheres estão decididas a mudar o mundo". [...] Isso não é, na verdade, um problema gramatical mas ideológico. [...] Escrevi então, a todas, uma a uma, acusando suas cartas e agradecendo a excelente ajuda que me haviam dado. Daquela data até hoje me refiro sempre a mulher e homem ou seres humanos. Prefiro, às vezes, enfeiar a frase explicitando, contudo, minha recusa à linguagem machista (ibidem, 1999, p. 66-68).

A escritora feminista, negra, norte-americana bell hooks ${ }^{3}$, foi uma das mulheres que dialogaram com Paulo Freire e reconhece nele um marco na sua trajetória de construção do feminismo negro:

Anos antes de encontrar Paulo Freire, aprendi muito com seu trabalho - aprendi novas maneiras de pensar sobre a realidade social. [...] Quando me encontrei com o trabalho de Freire, exatamente num momento da minha vida em que começava a questionar profundamente as políticas de dominação, o impacto do racismo, o sexismo, a exploração de classe e o tipo de colonização doméstica que existe nos Estados Unidos, senti-me profundamente identificada com os agricultores marginalizados dos quais ele falava, ou com meus irmãos e minhas irmãs negras da Guiné-Bissau.[...] Ele me fez pensar sobre a construção de uma identidade na resistência. Existe uma frase de Freire que se tornou um mantra revolucionário para mim: "Nós não podemos entrar na luta como objetos para nos tornarmos sujeitos mais tarde". [...] Esta experiência posicionou Freire em minhas mãos e no meu coração como um professor desafiador, de 
quem o trabalho ampliou minha própria luta contra o processo colonizador (bell hooks, 2013, p.65-66).

Ler Paulo Freire nos ensina a pensar com, num outro horizonte ético e epistêmico de construção do conhecimento, como apostas que se dirigem à libertação das correntes que dominam e oprimem, referimo-nos ao pensar não como solipsismo, mas como pôr-se em movimento de transformação.

Em tempos de desencanto, de distopias, revisitar os escritos de Paulo Freire, educador da liberdade, torna-se exigência existencial com atualidade comum aos clássicos. Já na justificativa de Pedagogia do Oprimido, que completou 50 anos de sua $1^{\text {a }}$ edição em 2018, temos:

Mais uma vez os homens desafiados pela dramaticidade da hora
atual, se propõem a si mesmos como problema. Descobrem que
pouco sabem de si, de seu "posto no cosmos", e se inquietam
por saber mais. Estará, aliás, no reconhecimento do seu pouco
saber se si uma das razões desta procura. Ao se instalarem na
quase, senão trágica descoberta do seu pouco saber de si, se
fazem problema a eles mesmos. Indagam. Respondem, e suas
respostas os levam a novas perguntas. O problema da huma-
nização, apesar de sempre dever haver sido, de um ponto de
vista axiológico, o seu problema central, assume, hoje, caráter
de preocupação iniludível (FREIRE, 1987, p. 29).

Como um dos intelectuais latino-americanos que problematizou a dimensão colonial da educação, abordando-a como prática histórica de dominação e opressão, portanto, de desumanização Freire, além de desvelar as facetas da educação opressora desenvolveu uma filosofia da educação libertadora na qual a dialogicidade, são princípios centrais. Isto nos leva a pensar que toda ação de colonização, dominação/ opressão, cotidiana e macro política, são ações de negação do diálogo, pois negar o direito a palavra é condição para desumanização, objetificando o outro. Portanto, aliada a outras ações, atuar na (re)educação da capacidade humana de dialogar é condição para rompermos com a reprodução das violências do colonialismo.

Na lógica colonial o conhecimento justifica poder, poder para saber com relações pedagógicas criadas voltadas à homogeneização e apagamento das diversidades. Enrique Dussel (2005, p. 55-70) argumenta que o processo de conquista europeia, iniciado em 1492, inaugura a primeira modernidade, sob liderança de Espanha e Portugal, potências do velho continente, tornado possível o surgimento da Europa como o bloco hegemônico, centro do sistema-mundo. Segundo o autor, sem os territórios e recursos provenientes da América, a segunda modernidade europeia não teria sido possível. Os poderes que se consolidam a partir do século XVIII, desde França e Inglaterra, e encontraram o que comumente entendemos como "cultura moderna", negam estrategicamente a primeira modernidade espanhola e portuguesa, assimilando-a ao obscurantismo medieval. 
Consequentemente, os sistemas educacionais modernos são estabelecidos como estratégicos no projeto de colonialidade de poder e de saber, pois escolarizar o mundo ${ }^{4}$ nos marcos da modernidade europeia é ato fundador da pedagogia em sua força colonial, perpetuando e aprofundando o projeto civilizatório delineado por ela. A pedagogia crítica não pode continuar a habitar neste silêncio apenas disputando educação para todos, há que se discutir que educação e quem são "todos".

Quijano (2005) utiliza o termo colonialidade para se referir à experiência específica da conquista e colonização que gestou padrões de dominação sem precedentes na história até o século $\mathrm{XV}$, sendo a ideia de raça uma categoria mental da modernidade que legitima a violência colonial construindo mentalidades pautadas na noção de inferioridades entre povos e culturas:

Na América, a ideia de raça foi uma maneira de outorgar legitimidade às relações de dominação impostas pela conquista. A posterior constituição da Europa como nova id-entidade depois da América e a expansão do colonialismo europeu ao resto do mundo conduziram à elaboração da perspectiva eurocêntrica do conhecimento e com ela à elaboração teórica da ideia de raça como naturalização dessas relações coloniais de dominação entre europeus e não-europeus (QUIJANO, 2005, p. 229).

A colonialidade diz respeito a histórias, formas de vida, saberes e subjetividades colonizadas engendradas em lógicas binárias, dualistas:

De acordo com esta perspectiva, a modernidade e a racionalidade foram imaginadas como experiências e produtos exclusivamente europeus. Desse ponto de vista, as relações intersubjetivas e culturais entre a Europa, ou, melhor dizendo, a Europa Ocidental, e o restante do mundo, foram codificadas num jogo inteiro de novas categoriais: Oriente-Ocidente, primitivo-civilizado, mágico/mítico-científico, irracional-racional, tradicional-moderno. Em suma, Europa e não Europa (Idem, p. 238).

A perspectiva de superioridade/inferioridade revela o racismo epistêmico no qual somente conhecimentos produzidos pelos brancos são qualificados como científico, objetivo e racional. A colonialidade do saber, não apenas estabelece o eurocentrismo como perspectiva única de conhecimento, mas também descarta as outras formas de vida e de produção intelectual. É sob a égide da colonialidade do saber, aliada a colonialidade do poder, que se consolidou o modelo de escola e universidade modernas, onde se insere o modo de produção filosófica hegemônico.

O que entendemos por Filosofia está mergulhado nas relações colonialidade/modernidade e esta área de conhecimento não é vista 
como um contínuo movimento de saberes de todas as parte do mundo, de encontro de povos, que na maioria dos casos se deu no confronto, na violência colonial, promovendo, também, epistemicídios, ou seja, assassinando, negando a produção de conhecimento de determinados povos, no caso brasileiro, o negro e indígena. Conforme Renato Nogueira, o epistemicídio representa o racismo na produção intelectual ${ }^{5}$.

Iniciamos com estas considerações para tecermos reflexões sobre interculturalidade e dialogicidade como contribuições para a transformação da filosofia (FORNET-BETANCOURT; FREIRE), portanto, com contribuições para descolonização do pensar e no enfrentamento dos epistemicídios que se reproduzem a séculos.

\section{Dialogar e interculturalizar a filosofia}

No enfrentamento das "situações-limites", na busca de superação do colonialismo, dialogar, compreender o que significa dialogar, exercitar o diálogo não é algo fácil e ainda que este seja um tema inerente a natureza do filosofar, exige um olhar mais atento. $\mathrm{O}$ que significa diálogo?

Dialogar e filosofar caminham juntos, num quefazer como do aprender a nadar. Só se aprende nadar nadando, correndo o risco de afogamentos, arriscando, indo de braçada, buscando. Uma área de saber que se constitui na dialogicidade, não por acaso, é negada, achincalhada por autoritários, antidialógicos de ontem e de hoje.

Dialogar é provocar atravessamentos, transbordamentos, vertigens, deslocamentos. O físico David Bohm, em "Conversando sobre Diálogo" (1989) lembra que a palavra diálogos, na língua grega, remete a logos, "a palavra" ou melhor "o significado da palavra" e dia que significa "através de", não significando dois ou duplo. A imagem que a origem da palavra sugere, é de uma corrente de significados, de fluidez, entre e através de nós. A fluidez altera, é algo criativo, representa compartilhamento (BOHM, 1989, p. 2).

Para o filósofo cubano-alemão Raúl Fornet-Betancourt (2001) a interculturalidade, assim como o diálogo, são aspectos intrínsecos ao filosofar, mas a filosofia ocidental por ter tomado rumos visando caracterizar-se como um saber com pretensões universais deixa de declarar sua dimensão intercultural, pois, universalidade e interculturalidade representariam uma contradição.

A cultura, então, é concebida como um obstáculo às pretensões universalizantes levando a necessidade de filtrar resquícios que contaminam a "pureza" filosófica. Por outro lado, é inegável que cada região tenha desenvolvido uma sensibilidade para determinados temas: é possível falar de uma tradição alemã, da fenomenologia francesa, da analítica norte-americana, da libertação latino-americana e africana, etc. 
Ao olharmos para "as geografias" da filosofia chama atenção suas dimensões circunstanciais, portanto, culturais, especificidades linguísticas de filosofares plurais que em diálogos com tradições são revisitadas, criticadas, superadas.

A preposição inter de intercultural não é um quantitativo, mas qualitativo. Nos convida a observar a filosofia como um saber como espaço compartilhado por uma ou mais culturas. Encontro com o outro não é algo novo na Filosofia, ao contrário, faz parte de sua própria natureza e a sua vocação à interculturalidade pode ser historicamente comprovada, reconhecendo que filosofar é uma saber memorial em diálogo com tradições culturais:

Falar da Filosofia intercultural significa, portanto, recolocar a filosofia no seu espaço e tempo, voltar às suas origens históricas, restituir seu passado. De fato, a filosofia nasceu no Egito faraônico como "ocasião, espaço e lugar" de diálogo intercultural, por receber e acolher estudiosos, pensadores e curiosos de todo o mundo, inclusive do Oriente e da Grécia. O que significa que, como observou o filósofo britânico Martin Bernal, a civilização grega antiga, considerada como "civilização clássica" pela Europa moderna, não constitui uma concentração cultural sui generis. Foi, na realidade, uma civilização híbrida, inspirada pela África, por intermédio do Egito antigo, e pela Ásia. Por conseguinte, a Filosofia nasce, essencialmente, como fruto de um diálogo intercultural. Certamente, a Filosofia clássica grega não se limitou numa simples tarefa de inculturação filosófica, mas não prescindiu desta ou do diálogo intercultural no qual nasceu. Desta forma, os principais filósofos gregos, que se formaram no Antigo Egito, levaram consigo a cultura intelectual e científica que receberam dos filósofos egípcios, da mesma maneira como hoje os filósofos e cientistas da "periferia do mundo", que se formam em diversas partes da Europa e da América do Norte, levam consigo aos próprios países a cultura intelectual e científica que receberam nesses lugares. Poder-se-ia dizer, inclusive, que todo intelectual "periférico" é, na sua essência, um intelectual intercultural. Desde a Conquista do Novo Mundo, embora o mundo não se reduza ao Ocidente, o Ocidente tornou-se "o Mundo" no qual todos nós nascemos e somos obrigados a viver. E é precisamente dentro deste horizonte de consciência cultural, política e geopolítica que, a partir dos anos 90, se intensifica o debate em volta da questão da filosofia intercultural como Filosofia "do nosso e para o nosso tempo", conforme sustenta o filósofo cubano Raúl Fornet-Betancourt (FRACCALVIERI, 2008)

Caminhos percorridos pela filosofia ocidental produziu o apagamento do filosofar como pluralidade, expressando sua face colonial, pois se o filosofar expressa o pensar, o assombro diante da condição existencial e do mundo, parece óbvio que este ofício é humano. O filósofo catalão-indiano, Raimon Panikkar, sugere que é necessário "desarmar 
a razão armada" (2002, p. 193) lembrando-nos que mesmo no ocidente o que se entende por filosofia é diverso, portanto, ao nosso entender, cabe a quem se dedica a ela dizer sua perspectiva filosófica, em que caminhos trilha, pois separar filosofia e contextos de sua produção é seguir armando a razão contra outras racionalidades, portanto, atuando colonialmente. Que armas utilizar para desarmar a razão?

Eu escrevi que entendo por filosofia mais a sabedoria do amor, do que o amor à sabedoria; entendo sabedoria no sentido mais latino e clássico de sapiente ciência que gosta e tem experiência do que seja esta força que se chama o amor. A partir dessa concepção, poder-se-ia revalorizar o que no ocidente eu considero hoje a função primária da filosofia, que eu resumiria num ponto: trata-se da superação da dicotomia entre teoria e práxis. Se a filosofia é apenas a atividade teorética - no melhor sentido da palavras - eu acredito que a experiência de alguns séculos até agora mostra-nos suficientemente sua infecundidade, para que nós formulemos mais radicalmente o que seja a atividade filosófica. E se a filosofia for apenas práxis, teremos não apenas uma função primariamente destrutiva, mas, subrepticiamente, essa atividade também pressupõe uma teoria. Eu acredito que é função da filosofia superar essa dicotomia entre práxis e teoria. Por isso, uma vez mais denominei filosofia como estilo de vida. [...] Por último, poderíamos indicar o que deveria ser, desde meu ponto de vista, uma atividade filosófica - e dou-me perfeitamente conta da ambição e do risco que essa afirmação pressupõe: tratar-se-ia de pôr em julgamento os últimos seis mil anos de experiência humana. Perguntar criticamente se o projeto homem que o homo historicus realizou nesses seis mil anos de história é o único projeto humano possível, e, por outro lado, ver se hoje não se deveria fazer diferente. Eu disse desarmar a razão armada e não armar a práxis. A luta é dialética. Trata-se de uma eris dialogal (PANIKKAR, 2002, p. 195-196).

Voltamos ao diálogo como princípio do filosofar e considerando que contemporaneamente felizmente temos vivenciado significativos debates e elaborações, em distintos campos de conhecimentos como da Filosofia Africana, Filosofia da Libertação, Estudos Pós-coloniais entre outros, que expressam possibilidades de mudanças de paradigmas, intuímos que os temas dialogicidade e interculturalidade contém relevância nos rumos de outro mundo possível, que nos desafia a pensar o pensado.

De acordo que contextualizar e reconhecer a diversidade é um primeiro passo ao filosofar descolonizado, consideramos que deve ser objeto da filosofia o que Paulo Freire destaca em Pedagogia do Oprimido:

[...] tem que ser forjada com ele e não para ele, enquanto homem ou povos, na luta incessante de recuperação da humanidade. Pedagogia que faça da opressão e suas causas objeto de reflexão dos oprimidos, de que resultará o seu engajamento necessário 
na luta por sua libertação, em que esta pedagogia se fará e refará (FREIRE, 1987, p. 32).

Soma-se, portanto, a esta rede de reflexões o tema da libertação, pois a história nos mostra a reprodução da dominação e opressão e traz a advertência: aprender com os erros, reavaliar seus continuísmos e revisar modelos de manutenção; reinventar métodos, enfrentar desafios epistêmicos, éticos, estéticos, políticos, hermenêuticos, questões que Raúl Fornet-Betancourt chama a atenção ao propor a reorientação intercultural da filosofia, que localizamos já presente em "Os Condenados da Terra" de Frantz Fanon ao abordar a descolonização:

A descolonização, que se propõe a mudar a ordem do mundo, é, como se vê, um programa de desordem absoluta. [...] é verdadeiramente a criação de homens novos. [...] há pois exigência de um questionamento integral da situação colonial (FANON, 2005, p. 52-53)

A filosofia ocidental tornou-se aliada de modelos que impõem uniformidade, homogeneização, monoculturas mentais e sociais indo na contramão de sua própria gênese de ser ferramenta de combate, de saber intempestivo provocadora de deslocamentos. O convite ao reconhecimento da dimensão intercultural da filosofia reconecta-a ao saber como memória subversiva que não se acomoda, mas interfere explicitando a lembrança de que o mundo é plural e não atua num ritmo único.

No contexto destas reflexões destacamos o que estamos chamando de filosofia vai de encontro a interculturalidade como vivência filosófica, tal como proposta por Fornet-Betancourt. Nossa inspiração olha para a enunciação teórica da filosofia intercultural e a prática educacional concreta, que se deseja libertadora. Como educadora interessa-nos retroalimentar as contribuições destas complexas discussões, qual seja, dos desafios da filosofia intercultural como chave do que temos chamado de reaprendizagem do pensar.

A isso devemos acrescentar que, embora a ideia de interculturalidade não esteja explicitamente presente nas conceituações de Paulo Freire sua prática educativa, sua vida foi intercultural e seu exercício foi de um filosofar desarmado e de novo tipo, em torno dos desafios da libertação como ato amoroso que se faz pelos oprimidos:

A violência dos opressores, que os faz também, desumanizados, não instaura uma outra vocação - a do ser menos. Como distorção do ser mais, o ser menos leva os oprimidos, cedo ou tarde, a lutar contra quem os fez menos. E esta luta somente tem sentido quando os oprimidos, ao buscarem recuperar sua humanidade, que é uma forma de criá-la, não se sentem idealisticamente opressores, nem se tornam, de fato, opressores do opressores, mas restauradores da humanidade de ambos. [...] Este ensinamento e este aprendizado têm de partir, porém, dos 
"condenados da terra", dos oprimidos, dos esfarrapados do mundo e dos que com eles realmente se solidarizam. [...] Luta que, pela finalidade que lhe derem os oprimidos, será um ato de amor, com o qual se oporão ao desamor contido na violência dos opressores, até mesmo quando este se revista de falsa generosidade referida (FREIRE, p. 31-32, 1987).

Paulo Freire e Frantz Fanon inspiram caminhos para a construção de "inéditos viáveis", dialógicos e interculturais, pois à descolonização do pensar situam complexos movimentos de libertação a serem gestados.

Freire solidariamente aprofunda o denunciado por Frantz Fanon em "Os Condenados da Terra". Principalmente nos livros "A Educação como Prática de Liberdade" (1959) e "Pedagogia do Oprimido" (1968) é possível identificar um diálogo sobre a violência gerada pela situação colonial e os impactos desta no colonizados, questão central de "Os Condenados da Terra".

Freire articula "situação colonial" presente em Fanon com "situação de opressão", na dialética opressor x oprimido. Em pedagogia do oprimido aprofunda estas questões como crítica a educação e política opressoras, indicando a necessidade de outro paradigma: educação dialógica como educação cultural libertadora.

Problematizando a construção das subjetividades colonizadas Fanon e Freire devem ser lidos lado a lado, pois nos auxiliam a compreender atitudes fatalistas, infelizmente muito atuais, como "é assim por vontade de Deus", a alienação religiosa, os populismos e a construção de mitos. Assim como o sentimento de querer ser como opressor, enaltecer o "patrão"; o "bem sucedido", a valorização da meritocracia como valor, a desvalorização de si, o sentimento de incapacidade e negação permanente de seus saberes, experiências e lutas. Ou seja, suas análises se complementam como uma fotografia dos padrões coloniais de dominação e opressão com grande atualidade.

Aproximando deste diálogo reflexões contemporâneas de Fornet-Betancount temos o desafio gigantesco na educação, formadora dos intelectuais que seguem reproduzindo a lógica colonial-burguesa. Refiro-me aos intelectuais no sentido estrito do termo, que se ocupam de funções ditas intelectuais, tais como profissionais na educação, onde nos inserimos, professores e professoras.

Fanon realiza uma análise crítica sobre os intelectuais colonizados que assimilam a cultura dominante e tem fascínio pela cultura do colonizador. Situando o sonho da descolonização das mentalidades nos diz:

Deixemos essa Europa que fala sem parar do homem e ao mesmo tempo o massacra em todos os lugares em que o encontra, em todas as esquinas de suas próprias ruas, em todos os cantos do mundo. [...] A Europa assumiu a direção do mundo com ardor, cinismo e violência. E vejam como a sombra dos seus monumentos se estendem e se multiplica. [...] A Europa se recusou a toda humildade, a toda modéstia, mas também a toda solicitude, a toda ternura. [...] Então, irmãos, como não 
compreender que temos algo melhor a fazer do que seguir essa Europa? (FANON, 2005, p. 361-62).

Entre os monumentos coloniais que se estendem pelo mundo temos modelos de filosofia como suas práticas monoculturais de pensar. A filosofia intercultural ao tratar da temática da cultura, da interculturalidade, convida a própria filosofia a repensar a si mesma para além de um único marco cultural. Exercitar a interculturalidade é partir da própria cultura, reconhecer-se desde um lugar, de uma tradição cultural, porém, conhecendo-a, vivenciando-a e questionando-a não tomá-la como absoluta, como um único marco interpretativo. Este olhar sobre a cultura a coloca na condição de intercomunicação, de ponte pela qual passamos e transitamos para chegar à outra margem, possibilitando o diálogo intercultural como crítica da cultura que, também, promove a desobediência cultural.

Se o que caracteriza o filosofar é o modo de olharmos o mundo, vivemos numa simbiose com os modelos filosóficos transplantados e o desafio de pensar desde nosso solo, espaço e tempo. A filosofia intercultural e os estudos sobre colonialidade explicitam como vêm se dando os processos de opressão/dominação que se manifestam nas inúmeras vozes que não falam na filosofia ocidental-europeia: indígenas, negras, das mulheres, das infâncias e das juventudes marginalizadas na América Latina.

Raúl Fornet Betancourt $(2001 ; 2004)$ defende a interculturalidade não como uma posição teórica ou como um diálogo entre culturas ou tradições filosóficas, mas como uma "posição" ou "disposição", um "modo de vida". Uma atitude de disposição a vivermos 'nossos' referenciais de identidade em relação aos 'outros'. Se trata de uma atitude que abre o ser humano em direção a um processo de reaprendizagem, realocação cultural e contextual, que por nos tirar de nossas certezas teóricas e práticas, nos permite perceber o analfabetismo cultural que nós somos culpados quando acreditamos que uma cultura é suficiente e a única apropriada para ler e interpretar o mundo.

Atuar dialogicamente e interculturalmente, se desejamos descolonizarmos, coloca-nos diante de desafios que só podem ser enfrentados superando o modo fragmentado de produção de conhecimento; desafios no campo da linguagem, da línguas, pois na América Latina temos a hegemonia de tradição colonial de apenas duas línguas de trabalho: espanhol e, em menor escala, o português se expressando como produtoras de conhecimentos.

As outras línguas faladas na América Latina não falam na filosofia latino-americana, assim como não falam nas demais áreas. Não se expressam em aimará, guarani, quíchua, nahuatl ou kuna, isto é, que esses povos não estão presentes com suas línguas e tradições gerando uma precariedade à abertura intercultural e uma indicação clara de uma persistente exercício colonizado do pensar (FORNET BETANCOURT, 2004, p.22-23). 
A interculturalidade, como entendida, é um dos caminhos possíveis para realização de processos de descolonização da reflexão filosófica iniciada por importantes pensadores latino-americanos. Neste aspecto é importante pensarmos as relações entre educação e filosofia, o que exige o questionamento acerca do modo como ambas são assumidas. Uma educação filosófica monocultural está a serviço da reprodução de subjetividades que historicamente vem sendo negadas, de saberes e lutas populares invisibilizados.

A proposta da filosofia intercultural vai de encontro a práticas anticoloniais, fazendo-se pedagogias descoloniais, onde as experiências de vida diversas se encontram, contribuindo, também, para a transformação da filosofia e de outras formas de produção de conhecimento de modo polifônico, fomentando o intercâmbio de saberes e não sacralizando, nem absolutizando uma cultura em detrimento de outra. Isso representa a renuncia à hermenêutica reducionista que opera com um único modelo teórico-conceitual como paradigma interpretativo. Descentralizadora a filosofia intercultural:

[...] não é somente antieurocêntrica, não só liberta a filosofia das amarras da tradição, europeia, mas sim, vai além, critica a vinculação dependente e exclusiva da filosofia com qualquer outro centro cultural, Assim, neste sentido, critica igualmente qualquer tendência latino-americana-centrista ou de afro-centrismo, etc. Sua visão é, pelo contrário, fixar a reflexão filosófica no momento da interconexão, da intercomunicação; e abrir um espaço, desse modo, à figura de uma razão inter-discursiva" (FORNET-BETANCOURT, 1994, p, 11).

Tal modo de conceber a filosofia remete a epistemologias vinculadas a ética e a política do encontro, da reciprocidade, promotora do diálogo entre distintos contextos e para isso busca exercer a reflexão acerca das condições históricas desse diálogo (BECKA, 2010 p. 88), expressando que a função da filosofia é interna a sociedade, ao seu contexto e o modifica. Onde as condições históricas impedem o diálogo o pensamento intercultural deve atuar promovendo o encontro:

A crítica das assimetrias existentes é, por isso, o primeiro dever de uma interculturalidade que vise uma práxis: ela quer não só interpretar o mundo interculturalmente, porém e acima de tudo, estruturá-lo interculturalmente. [...] A filosofia é sempre contextual, ela capta sua época em pensamento (BECKA: 2010 p. 87-88).

Levantamos, ainda, a hipótese de que nossas universidades, muitas vezes pressionadas por projetos políticos mais amplos, se encontram arraigadas a modelos de formação de educadores distante da emergência do diálogo intercultural, descolonial e libertador como promotor da pluralidade. Mesmo trazendo à tona o discurso da diferença, a problemática da inclusão acaba associando a diferença ao diferente, 
corporificando literalmente as diferenças e solidificando-as em identidades sociais, gerando estigmas e reinstaurando lógicas de segregação.

O ensino acadêmico que devemos examinar em uma perspectiva crítica, está regulado em grande parte, por planos de estudos cujos conteúdos nucleares não apenas refletem a "cultura científica" da sociedade hegemônica de ontem e de hoje, como que apontam a manutenção das condições epistêmicas necessárias para a perpetuação do conhecimento ou, dizendo com maior propriedade, do ideal do conhecimento que a sociedade hegemônica vende como universal.

A filosofia reduzida a leitura de textos acadêmicos gestou uma visão equivocada contribuindo para perder-se de sua real significação e sentido original, de confrontação prático-reflexiva com os contextos da vida. Ao invés de "ler" os contextos de vida, reduziu-se, no mais das vezes, em estudo de textos. No entanto, a filosofia não é tanto o estudo de textos, mas essencialmente um saber contextual: "Não é um mero saber ou aprender ideias ou sistemas de pensamento, senão, e sobretudo, um saber realidade e saber fazer realidade" (FORNET-BETANCOURT, 2000).

Mais do que uma nova orientação restrita a um campo disciplinar - filosofia - a interculturalidade é uma maneira de ver, uma atitude comprometida, um hábito intelectual. A perspectiva intercultural nas relações supõe uma valorização mútua de parte das culturas que interatuam. Portanto, exige de cada uma delas a consciência de seus limites e a disposição de aprender da outra sem dissolver sua própria originalidade, enriquecendo-a e enriquecendo-se incessantemente.

Transformar a filosofia, dialogicamente e interculturalmente, tem muito desafios tais como: a) estabelecer novos pressupostos hermenêuticos e epistemológicos do diálogo intercultural; b) realizar uma revisão crítica do pensamento latino-americano e do redescobrimento da América como lugar de mundos e de vida e de pensamentos plurais o que fundaria uma perspectiva intercultural e, c) reconhecer a atuar de modo interdisciplinar. (FORNET-BETANCOURT, 2000).

Do ponto de vista educativo este quefazer olhar processos de valorização da diversidade humana por meio do reconhecimento das memórias vigentes na historicidade corporal e contextual dos povos. Educar desde as memórias significa ativar diferentes tempos biográficos que marcam a vida, os lugares, seus ritmos e suas práticas. Significa a criação de uma pedagogia que combata o analfabetismo biográfico - pessoal e comunitário - comprometendo-se com os pertencimentos concretos de crianças, jovens e adultos, contribuindo para relerem suas histórias, suas tradições, seus saberes criticamente, sem se fechar cada um em suas diferenças, mas partindo delas se reconectem consigo mesmos e o mundo. Este quefazer é intercultural e coloca a diversidade humana concreta com suas temporalidades e espacialidades, em oposição a cronologia do calendário global.

É necessário que a humanidade recupere seus saberes contextuais, comunitários, como parte integrante da afirmação da diversidade 
epistêmica contra toda forma de colonialismo ou neocolonialismo mental, político, econômico. Este projeto alternativo se sustenta em inúmeras culturas que tem historicamente resistido e buscado recriado condições para que cada um possa levar uma vida digna dentro de seu universo cultural.

Com este olhar a filosofia intercultural persegue um duplo objetivo, por um lado uma mudança de paradigma em nível teórico que permita a reconstrução das racionalidades com base numa constelação de saberes da humanidade, por meio de diálogos abertos entre distintas tradições culturais. Por outro lado busca completar este giro teórico com uma proposta prática de reorganizar o mundo globalizado fazendo valer, contra as forças universalizantes e niveladoras, a voz dos povos que fazem do mundo um lugar plural, tendo em vista a realização de outra humanidade, com solidariedade real em que muitos mundos convivam entre si. (FORNET.BETANCOURT, 2003).

Este programa proposto por Fornet-Betancourt claramente dialoga com uma pedagogia da libertação e não é difícil reler Paulo Freire potencializando este paradigma da interculturalidade. Nesta perspectiva a pedagogia de Freire não deve ser convertida a instrumentos que possam contribuir para a tradução de culturas e contextos diversos, pois como filosofia da educação libertadora que contém elementos críticos e criativos, com epistemologia própria e clara posição ético-política entendemos que, somada aos desafios de alfabetização intercultural, podem contribuir para o fazer teórico-prático que enfrenta as problemáticas relações saber e poder que perpassam a educação em nosso continente.

A ampla produção de Paulo Freire é complexa e deve ser lida contextualmente. Suas reflexões passam por revisões autocriticas ao longo de sua trajetória e, portanto, muda em contextos. Ele não tematiza explicitamente a questão da educação intercultural, temas como negritude e educação indígena não estão explicitados. No entanto, analisar a ausência do tema educação intercultural, interculturalidade, sem contextualizá-lo pode nos levar a um anacronismo histórico pois a problemática da educação intercultural é relativamente recente e mal ganhava impulso momento da morte de Freire. Neste sentido nosso movimento é de estabelecer aproximações e não comparações.

Raúl Fornet-Betancourt, aponta que no contexto latino-americano o tema da interculturalidade é impulsionado por um evento muito significativo: o 1992 (2004, p. 25-26), ou seja, o contexto dos preparativos e comemorações de acordo interesses ideológicos, dos quinhentos anos da conquista, o encontro entre dois mundos, a invasão ou o início da evangelização.

Catherine Walsh (2009) destaca que desde os anos 90, a diversidade cultural na América Latina se transformou num tema em moda. Está presente nas políticas públicas e reformas educativas e constitucionais e constitui um eixo importante, tanto na esfera nacional-institucional como no âmbito inter/transnacional. Embora se possa argumentar que essa presença é fruto e resultado das lutas dos 
movimentos sociais-ancestrais e suas demandas por reconhecimento e direitos, pode ser vista, ao mesmo tempo, de outra perspectiva: a que a liga aos desenhos globais do poder, capital e mercado. Por isso, é importante contextualizar o debate e iluminar sua politização.

A interculturalidade passa a ser um termo usado para se referir a esses discursos, políticas, estratégias de corte multicultural-neoliberal. Seguindo Tubino (2005), citado por Catherine Walsh, podemos nomear essa interculturalidade como funcional, porque não questiona as regras do jogo e é perfeitamente compatível com a lógica do modelo neoliberal existente:

Enquanto no interculturalismo funcional busca-se promover o diálogo e a tolerância sem tocar as causas da assimetria social e cultural hoje vigentes, no interculturalismo crítico busca-se suprimi-las por métodos políticos não violentos. A assimetria social e a discriminação cultural tornam inviável o diálogo intercultural autêntico. [...] Para tornar real o diálogo, é preciso começar por tornar visíveis as causas do não diálogo. E isso passa necessariamente por um discurso de crítica social [...] um discurso preocupado por explicitar as condições [de índole social, econômica, política e educativa] para que este diálogo se dê. (TUBINO, 2005, p. 8 apud WALSH, 2009, p. 8)

O diálogo crítico e a compreensão dos padrões de poder, de exclusão, negação e subalternização ontológica e epistêmico-cognitiva dos grupos e sujeitos racializados, práticas de desumanização e de subordinação de conhecimentos que privilegiam alguns sobre outros, "naturalizando" a diferença e ocultando as desigualdades que se estruturam e se mantêm em seu interior são centrais na vivência da interculturalidade, atuando nas subjetividades.

É no horizonte crítico que situamos a interculturalidade e no diálogo com Paulo Freire, ainda que o tema interculturalidade não seja explicito em seus escritos, a diversidade cultural, a educação como ação cultural para liberdade é tematizada como reinvenção do poder, como ilustrado no diálogo com o filósofo chileno Antonio Faundez:

Na verdade, é impossível pensar esta questão, a da cultura, muito menos equacioná-la, fora de uma perspectiva de classe, sem referência ao poder de classe. E em função deste poder de classe que a cultura hegemônica, expressando a forma de estar sendo da classe dominante, se entende a si mesma como a única, a válida, a expressão real, enfim, da nação. O resto é inferior, é feio. O mesmo ocorre, naturalmente, com a sua linguagem, com a sua sintaxe, considerada como a única certa - o chamado padrão culto - a que as classes trabalhadoras terão de simplesmente curvar-se. [...] além de fazer prevalecer suas ideias, a classe dominante ainda tenta, através do poder de sua ideologia, fazer crer a todos que suas ideias são ideias da nação. [...] Ligada ao poder econômico e ao político,- cultura dominante tende a impor às demais expressões culturais a sua 
"superioridade". Por isso mesmo é que, rigorosamente, a decantada multiculturalidade de certas sociedades não existe. Para que, realmente, houvesse multiculturalidade, seria necessário que houvesse uma certa unidade na diversidade. E unidade na diversidade pressupõe o respeito mútuo das diferentes expressões culturais que compõem essa totalidade. Acho que, mais uma vez, estamos diante da questão da reinvenção do poder (FREIRE; FAUNDEZ, 1985, p. 88).

Reinventar o poder é, também, reinventar o saber, transgredir no modo como determinados conhecimentos são produzidos ou silenciados em detrimento de outros. Neste campo as filosofias latino-americanas da libertação tem atuado de forma criativa e, situando-se neste contexto Fornet-Betancourt, pontua quatro questões, que estão mutuamente interligadas e que considera as mais importantes para explicar o que denominou insuficiências interculturais da filosofia latino-americana com desafios para superação (2004, 23-26):

- A primeira é o uso colonizado da inteligência. Prática que não permite que se abra para a diversidade cultural de nosso continente, pois apesar de tentativas de superação, esta é uma prática que sobrevive explicitando uma herança colonial que se expressa, por exemplo, no modo de fazer filosofia estando em dia com a última moda da filosofia na Europa ou nos Estados Unidos da América, onde muitas vezes se busca mais o reconhecimento acadêmico como forma de sinal de credibilidade do que contribuir para o bem comum.

- A segunda está na opção metodológica de uso exclusivo de fontes escritas e da forma escrita de expressão, bem como a análise de textos e a produção de textos, ou seja, uma cultura filosófica exclusivamente escrita. Visão tributária do projeto de modernidade centro-europeia sob a qual se ensina e se reproduz estas práticas como únicos métodos de investigações filosóficas válidas, com forte vigência normativa na tradição acadêmica. Considerando que na América Latina a oralidade tem um papel muito importante na criação e transmissão da cultura, isso é uma deficiência grave e reveladora de um logos centrado num único modelo de racionalidade.

- A terceira questão, devido à opção pela escrita como única forma de investigação filosófica, a filosofia latino-americana conhece apenas duas línguas de trabalho: espanhol e português. "As outras línguas que se falam na América Latina não falam na filosofia latino-americana". O bilinguismo desta filosofia é para Fornet-Betancourt uma expressão contundente da precária abertura intercultural de nosso filosofar, pois não é possível compreender o outro e expressar nossa compreensão do outro se fixando em uma ou duas lógicas linguísticas.

- Por fim a quarta questão está na redução da diversidade cultural latino-americana a noção de "cultura mestiça". O fato de termos a mestiçagem como marca da cultura latino-americana 
é resultado, também, de relações interculturais, no entanto, é, também, marca do colonialismo, da perpetuação do racismo. Nem toda América Latina é mestiça e este conceito não expressa a diversidade cultural de nosso continente. Esse conceito expressa relações interculturais resultantes da pluralidade de culturas, mas reduzir esta pluralidade ao conceito de mestiçagem é um "ato de colonialismo cultural que dilui as diferenças e, na prática, oprime e marginaliza o outro".

Assumir a cultura como ponte é compreender a filosofia como cultural, portanto, pode haver tantas filosofias quanto há culturas e a interculturalidade representa o exercício de intercomunicação, interconexão, de forma crítica, sem sacralizar, mas atuando no reconhecimento, dialogicamente, como já pontuado anteriormente a filosofia intercultural é anticentrista:

Esse anticentrismo da "filosofia intercultural" não deve ser confundido, de modo algum, com uma negação ou desqualificação do âmbito cultural próprio correspondente. [...] Entendemos que se trata de sublinhar a dimensão crítica frente ao próprio, de não sacralizar a cultura que é nossa e de ceder as suas tendências etnocêntricas. É preciso partir da própria tradição cultural, conhecendo-a e vivendo-a, não como instalação absoluta, mas como trânsito e ponte a inter-comunicação (Idem, 1994, p. 11).

Outro aspecto a considerar é que conhecer a história do pensamento latino-americano é mais amplo que conhecer a história da filosofia latino-americana. Isso abarca a necessidade de conhecermos diferentes tradições de pensamento, desde nossa cultura - ponte da qual não é possível saltar - indo ao encontro das demais formas de pensar que não estão contempladas na filosofia até então reproduzida entre nós.

Diante dos desafios metodológicos, hermenêuticos e epistemológicos para a construção de modos interculturais de pensar, um giro fundamental está na ampliação das fontes do pensar, tais como a oralidade, as expressões culturais e as lutas políticas africanas, indígenas, reeducar o olhar acerca das infâncias como cultura, etc. Mais que ampliar o que será estudado significa ampliar, democratizar a participação dos sujeitos que falam na história da filosofia aceitando como filosóficas suas mensagens, seus problemas, suas questões.

Um movimento intercultural envolve um deslocamento cultural em direção de uma reaprendizagem do pensar que supere o pensamento monocultural, inculturado, desoncidentalizando, descolonizando, o modo como temos nos relacionado com filosofia e demais áreas de conhecimento. Trata-se de tomada de posição acerca do estilo de filosofar desde o lugar em que se situa e como se situa neste lugar e neste tempo histórico cultural. Tal exigência envolve-se num grande desafio teórico-metodológico voltado para outras fontes de saberes, conhecimentos e experiências culturais. É o reaprender a pensar em uma práxis 
dialógica, na diversidade, na multiplicidade que nos constitui como seres humanos (ibidem, p. 64).

À proposta de interculturação da filosofia, do pensar, somam-se o desenvolvimento de pensamentos proposicionais, num processo de elaboração que não privilegia nenhum sistema conceitual em detrimento de outro, pois reconhece-se como saber incompleto, circular, o que Fornet-Betancourt denomina de experiência de inter-trans-culturalização. Não é filosofia comparada instrumentalizando nosso modo de ser indo ao outro, trata-se de um encontro de diferentes vozes que buscando transformação, na qual só o outro pode comunicar sua palavra, não comunicamos por ele nem determinamos a ele como deve pensar, mutuamente nos reeducamos.

Reaprender a pensar desde a polifonia do pensamento ibero-americano é o verdadeiro começo de um processo filosófico intercultural ao nível dos desafios de nossa herança cultural. Pois é aqui onde aprendemos a relacionar-nos com nosso pensar, seja este indígena, afro americano ou europeu, desde a convivência com outras formas de pensamento. "Con-vivência onde experimentamos a possibilidade de transitar por vários "lugares" de palavras originárias e insubstituíveis em suas mensagens". (Ibidem, p. 67).

Este horizonte de reaprendizagem do pensar traz um pensar respectivo que é transformado à medida que é um sujeito que não conhece o outro, mas que conhece com o outro num processo continuo, mesmo que conflituoso, funda exercícios de inter-comunicação, interculturais, criando um novo modo de se fazer filosofia que será transfigurada pois se dá no reconhecimento e descobrimento das pluralidades humanas que nos constituem, questionando nossa evidências filosóficas, num mútuo questionamento sobre as formas de viver, de ser, de criar, etc. (ibidem, p. 70).

Como vimos, a dimensão intercultural do pensar proposta de Raúl Fornet-Betancourt trata do comprometimento com a dimensão social do conhecimento, em que epistemologias expressam cosmovisões de mundo e incidem sobre subjetividades culturalmente e politicamente constituídas. Visualizamos nesta proposta contemporânea elementos, alguns levantamos brevemente aqui, que em diálogo com contribuições de Paulo Freire, assim como com os estudos sobre colonialidade/ modernidade nos convidam a reinvenção de nós mesmos.

Num tempo histórico difícil em que no Brasil e no mundo nos deparamos quase impotentes com toda forma de atrocidades que revelam a força de um sistema global regido pela ganância, destruição dos ecossistemas e com permanente ameaças a vida, olhar para a diversidade humana, aprender com as diversas tradições de pensamento, reorientar estas tradições aprendendo com elas, em busca de uma convivência mais amorosa entre todos os seres parece uma luz no fim do túnel.

Como nos ensina a filosofia guarani, os caminhos que nos conduziram ao mal viver "são frequentemente revistos percorrendo uma história regressiva dos nossos erros e desvios - guerras, economias 
de mercado, capitalismo, ditaduras, consumismo, individualismo, empobrecimento - mas, somos de verdade conscientes de que estes caminhos não podem ser simplesmente 'des-caminhados', apagando as ingratas pegadas dos nossos 'pecados'? A queixa saudosa somente não abre caminho para o futuro." Na filosofia do bem viver guarani é necessário revermos o modo de ser e estar no mundo (tekó) buscando a experiência concreta de tekó porã, ou seja, a boa maneira de ser e viver. Tekó Porã é inter relação, reciprocidade. Como diz Bartolomeu Meliá: “Os povos e nações indígenas da América são a memória de nosso futuro e, se não existissem, teria que inventá-los. Como todos nós que já estamos na hora de inventar-nos novamente." (SCHNORR, 2019).

\section{Para não concluir...}

As palavras tecidas até aqui nos remetem a lembrança de que somos sempre comunidade. Como seres humano somos sempre comunitários! Re-conhecer esta dimensão situa, também, a materialidade da ética e política do filosofar como libertação e este filosofar nos desafia, talvez mais que ontem, a aprendermos a ser mais conectivos.

Uma pessoa conectiva pessoa pode ser explicada, simplesmente, pela conjunção ' $\mathrm{e}$ ', a menor palavra que existe para aproximar uma coisa de outra, uma pessoa de uma outra: 'eu e você' ou 'você e eu', a menor palavra que empregamos para somar, para acrescentar, para criar vínculos, para estabelecer interações, para pensar em equipe, para fundar o diálogo, para mudar o mundo." (BRANDÃO, 2001, p. 8)

Considerando nossa ainda limitada e recente experiência democrática, somada ao eterno retorno do autoritarismo, torna-se claro e translúcido a enormidade da relevância da ação-reflexão-ação aqui provocadas. Descolonizar nossas mentalidade passa, necessariamente, em ler nossos intelectuais, tais como Paulo Freire que:

Estava preocupado com a formação de uma mentalidade solidária, disposta a servir ao bem comum, desafio que superava em muito a tarefa de enfrentar o analfabetismo e exigiria do poder público a criação de condições institucionais e materiais à altura do desafio. $\mathrm{O}$ processo no qual Paulo Freire depositou suas esperanças foi bruscamente interrompido pelo golpe militar. O quietismo e o mutismo tão criticados por ele foram impostos por atos institucionais de um governo de exceção que se estendeu por mais de vinte anos. (SOUZA, 2001, p. 65).

O sonho possível da solidariedade, o "inédito viável" da democracia participativa e dialogada, a utopia factível de um mundo onde a opressão seja extinta pela colaboração liberadora dos sujeitos conectíveis, tudo isso prossegue tendo seu pleno valor em nosso presente histórico:

Por isto, o diálogo é uma exigência existencial. E, se ele é o encontro em que se solidarizam o refletir e o agir de seus sujeitos 
endereçados ao mundo a ser transformado e humanizado, não pode reduzir-se a um ato de depositar ideias de um sujeito no outro, nem tampouco tornar-se simples troca de ideias a serem consumidas pelos permutantes. (FREIRE,1997, p. 0).

Se é certo que parte da filosofia que se re-produz nas instituições estão alheias as vidas humanas, ao seu contexto e voltam-se para si mesmo, ao mero estudo dos textos de filósofos e se a crítica ao modo de fazer filosofia profissionalmente é necessária, no entanto, o processo de desenvolvimento sócio-político contemporâneo e a crescente expansão do capital em sua lógica desumanizante, excludente, tem convocado a filosofia, como outras áreas de conhecimento, a expressarem suas forças de resistência e de inovação, com capacidade questionadora e no movimento de nos ajudar a "ler o mundo" e nele reaprender a viver.

Se por um lado num mundo programado como globalização do neoliberalismo não há lugar para a filosofia. Por quê? Como nos lembra Fornet-Betancourt (2001), porque a filosofia, apesar das cumplicidades ao longo de sua história e de ter jogado um papel significativo na justificação teórica ideologia do colonialismo, conseguiu preservar e transmitir muitas histórias paralelas de caráter subversivo e de sabedoria e sempre nos lembra a não fazer as pazes com as condições dadas da realidade porque esta poderia ter sido de outra forma, pois filosofar é resistir, é pensar e este devir é humano.

A filosofia narra e incentiva a pesquisa da memória em busca da verdade e da justiça dos seres humanos e dos povos. Porque a filosofia é sabedoria memorial, é sabedoria do amor (PANIKKAR, 2002), mais que mero amor à sabedoria e, enquanto tal, nos impulsiona a não nos contentarmos com o estado de coisas. Essa dimensão memorial da filosofia contradiz o tipo de ser humano que o sistema hegemônico visa construir e se aproxima da concepção de ontológica de Freire como ser mais. Portanto a irrelevância da filosofia está em atuar contra o apagamento das memórias coletivas, das ancestralidades, das humanidades possíveis que o filosofar tece.

A filosofia nos lembra que o mundo pode ser reduzido ao mercado mundial submetido ao ritmo do consumismo, da ganância, da intolerância, dos discursos de ódio e de morte. Como saber memorial a filosofia não é deste ou daquele filósofo, é memória cosmológica de uma humanidade plural, portanto, diversa, que habita o mundo de muitas formas, como saber memorial a filosofia é cultivo da consciência, da sabedoria de que o mundo é a casa que habitamos, portanto, detentora de culturas, de éticas, de epistemologias, de formas de vida marcadas por singularidades.

\section{Referências}

BECKA, Michelle. Interculturalidade no pensamento de Raúl Fornet-Betancourt. São Leopoldo: Nova Harmonia, 2010. 
bell hooks. Ensinando a transgredir: a educação como prática da liberdade. São Paulo: Editora WMF Martins Fontes, 2013.

BRANDÃO, Carlos Rodrigues. Hoje, tantos anos depois. In: SOUZA, Ana Inês. Paulo Freire: vida e obra. São Paulo: Editora Expressão Popular, 2001.

BOHM, David. O Diálogo. Corresponde a uma edição dos registros de um encontro que aconteceu em 1989, na cidade de Ojai próxima a Ventura ao Norte de Los Angeles. A transcrição inglesa editada, foi corrigida e aprovada pelo Dr. Bohm.

DUSSEL, Enrique. Europa, modernidade e eurocentrismo. In: LANDER, Edgardo (Org.). A colonialidade do saber. Eurocentrismo e Ciências Sociais. Perspectivas Latino-Americanas. Buenos Aires: CLACSO, 2005.

FANON, Frantz. Os Condenados da Terra. Juiz de Fora: Ed. UFJF, 2005.

FRANCCALVIERE, Bianca. Filosofia Intercultural, 2008. Entrevista mimeo com Raúl Fornet-Betancourt.

FREIRE, Paulo. Educação como Prática de Liberdade. $26^{\mathrm{a}}$ Ed. Rio de Janeiro: Paz e Terra, 2002.

Extensão ou Comunicação? Rio de Janeiro: Paz e Terra, 2010.

Pedagogia da Esperança: Um reencontro com pedagogia do oprimido. 6a Ed. Rio de Janeiro: Paz e Terra, 1999.

. Pedagogia da Autonomia: saberes necessários à prático educativa. São Paulo: Paz e Terra, 1997.

Terra, 1987.

Pedagogia do Oprimido. 17a ed. Rio de Janeiro: Paz e

FREIRE, Paulo; FAUNDEZ, Antonio. Por uma pedagogia da pergunta. Rio de Janeiro: paz e Terra, 1985.

FORNET-BETANCOURT, Raúl. “Filosofía Latinoamericana: ¿Posibilidad o Realidad?", Estudios de Filosofía Latinoamericana, México, Universidad Nacional Autónoma de México, 1992.

Questões de método para uma filosofia intercultural a partir da Ibero-América. São Leopoldo; Ed. UNISINOS, 1994. 
. Transformación intercultural de la filosofia latino-americana: ejercicios teóricos y práticos de la filosofía intercultural en el contexto de la globalización. Desclée de Brouwer, 2001.

. La interculturalidad a prueba. Aachen: Revista Concórdia, Band 43, 2006.

Filosofar para nuestro tiempo en clave intercultural. Wissenschaftsverlag Mainz, Aachen, 2004a.

. Interculturalidade, críticas, diálogos e perspectivas. São Leopoldo: Nova Harmonia, 2004b.

PANIKKAR, Raimon. A dialética da razão armada. In: GÓMEZ-MULLER, Alfredo; FORNET-BETANCOURT, Raúl. Posições Atuais da Filosofia Européia. São Leopoldo: Editora Nova Harmonia, 2002.

QUIJANO, Aníbal. Colonialidade do poder, eurocentrismo e América Latina. In: LANDER, Edgardo (Org.). A colonialidade do saber. Eurocentrismo e Ciências Sociais. Perspectivas Latino-Americanas. Buenos Aires: CLACSO, 2005.

SCHNORR, Giselle Moura. Filosofia indígena. Sim, temos! Jornal Caiçara, União da Vitória, 28/06/2019. Disponível em: http:/ /www. jornalcaicara.com.br/colunas/filosofia-indigena-sim-temos/

SCHNORR, Giselle Moura. A Filosofia intercultural de Raúl Fornet-Betancourt: práxis dialógica e reaprendizagem do pensar. Tese de doutorado. Universidade de São Paulo: USP, São Paulo, 2015.

SOUZA, Ana Inês. Paulo Freire: vida e obra. São Paulo: Editora Expressão Popular, 2001.

TUBINO, Fidel. La interculturalidad crítica como proyecto ético-político, Encuentro continental de educadores agustinos, Lima, enero 2005. Apud: WALSH, Catherine. Interculturalidade Crítica e Pedagogia Decolonial: in-surgir, re-existir e reviver. In: CANDAU, Vera Maria (org.). Educação Intercultural na América Latina: entre concepções, tensões e propostas, 2009.

WALSH, Catherine. Interculturalidade Crítica e Pedagogia Decolonial: in-surgir, re-existir e reviver. In: CANDAU, Vera Maria (org.). Educação Intercultural na América Latina: entre concepções, tensões e propostas, 2009. 